Revista Docência do Ensino

Superior

v. 1, 2011

\section{EXPERIÊNCIA EM EAD NO CURSO DE DESIGN DA UFMG}

\author{
EXPERIENCE IN DISTANCE LEARNING IN DESIGN \\ COURSE AT THE UFMG
}

Andréa Franco Pereira

\section{UFMG}

andreafranco@taskmail.com.br

\section{RESUMO}

A absorção de novas mídias elaboradas a partir da junção de informática, telecomunicações e Internet vem favorecendo a ampliação das práticas de ensino a distância (EAD) no Brasil e no mundo. Para além de permitir que indivíduos dispersos geograficamente possam ter acesso à educação formal, atualmente o EAD se apresenta como meio de viabilizar oportunidades que venham favorecer maior flexibilização do ensino na graduação. Demandas tais como o aumento de vagas eletivas ou o ingresso em disciplinas optativas ofertadas em horários sobrepostos somente podem ser viabilizadas adequadamente a partir de Ambientes Virtuais de Aprendizagem e em atividades não presenciais. Nesse sentido, este artigo busca compartilhar a experiência de duas disciplinas ofertadas em EAD pelo Colegiado de Graduação do Curso de Design da Universidade Federal de Minas Gerais (UFMG), apresentando a abordagem adotada e os Objetos Virtuais de Aprendizagem desenvolvidos.

Palavras-Chave: EaD. Design. Metodologia. Inovação. Curso de graduação.

\section{ABSTRACT}

The absorption of new media, elaborated from the junction of informatics, telecommunications and the Internet, are encouraging the expansion of distance learning practices in Brazil and in the world. Besides allowing geographically scattered individuals to having access to formal education, distance learning today is a way to attend to opportunities that could provide more flexibility at undergraduate courses. Demands such as the increase in elective openings in courses or application for courses offered in overlapped schedules, can only be properly taken through Virtual Learning Environments and in non-onsite activities. In this sense, this article seeks to share the experience of two distance learning courses offered in the undergraduate Design Course at UFMG, presenting the adopted approach and the Virtual Objects of Learning developed.

Keywords: Distance learning. Design. Methodology. Innovation. Undergraduate course.
Universidade Federal de Minas Gerais

Correspondência/Contato

Av. Antônio Carlos, 6627

Pampulha: 31270-901

BELO HORIZONTE - MG

revistadocenciadoensinosuperior@ufmg.br

Coordenação

Rede de desenvolvimento de práticas de Ensino Superior - Giz/Prograd 


\section{INTRODUÇÃO}

A atividade de ensino a distância (EAD) não é uma prática muito recente. Suas origens estão em iniciativas de educação por correspondência adotadas em meados do século XIX na Europa e nos EUA, que tiveram o intuito de suprir a necessidade de aprendizado de pessoas que, por algum motivo, não podiam estar presentes em salas de aula tradicionais (MELLO et al., 2010). No decorrer do tempo, a essa ideia foram sendo apropriadas as novas tecnologias que surgiam, tais como as telecomunicações, permitindo que um maior número de pessoas pudesse ser beneficiado pelo aprendizado e educação formal.

Pode-se dizer que no Brasil o EAD toma nova dimensão a partir da década de 1990, em razão da Lei de Diretrizes e Bases da Educação Nacional (Lei no 9.394/96), em seu artigo 80 (PIMENTEL et al., 2010), que “instituiu a educação a distância como uma forma de ensino equivalente ao presencial em todos os níveis" (CRUZ, 2008). Também pela absorção de novas mídias elaboradas a partir da junção da informática, telecomunicações e Internet. Segundo o Anuário Brasileiro Estatístico de Educação a Distância, cerca de 2,5 milhões de brasileiros estudam em cursos na modalidade EAD (ABRAEAD, 2011).

Atualmente, o ensino a distância não é mais visto somente como a "educação ou formação adaptada a indivíduos que estão geograficamente dispersos ou separados fisicamente do instrutor" (segundo BELANGER, 2001 apud MELLO et al., 2010, grifos nossos), novas demandas ou oportunidades vêm se fazendo presentes, favorecendo maior flexibilização do ensino.

Nesse sentido, este artigo busca compartilhar a experiência de duas disciplinas ofertadas em EAD pelo Colegiado de Graduação do Curso de Design da Universidade Federal de Minas Gerais (UFMG). A adoção do sistema EAD nesses casos foi vista como oportunidade: 1) de ampliar o número de vagas eletivas para alunos oriundos dos diversos cursos da universidade - exemplo da disciplina Noções de Design (UNI 015) e 2) de permitir que os alunos do Curso de Design pudessem cursar maior número de disciplinas optativas que, ao contrário, sendo em situações presenciais, apresentariam sobreposição de horários - exemplo da disciplina Ecodesign e Meio Ambiente (TAU 070).

O artigo apresenta a abordagem adotada para se criar uma dinâmica de interação entre os participantes das disciplinas, baseada nas relações aluno-professor e 
aluno-aluno e, com base nisso, mostra como foram elaborados os Objetos Virtuais de Aprendizagem. Serão descritas as experiências das duas disciplinas e o aprendizado adquirido nessa vivência, que contribuiu para a revisão de conteúdos e dinâmica, e ajustes para as edições posteriores.

\section{2. ABORDAGEM DE ENSINO-APRENDIZAGEM ADOTADA}

De acordo com Pimentel et al. (2010), não existe um modelo único para aplicação do EAD e "as próprias mudanças decorrentes da integração das mídias e do avanço tecnológico estão moldando novas formas de educar e aprender a distância" (PIMENTEL et al., 2010, p. 212).

Embora, diversos estudos têm pontuado a importância de se considerar as necessárias diferenças entre as práticas adotadas pelo ensino presencial tradicional e pelo EAD (MACHADO, 2010a; CRUZ, 2008; MORAN, 2000), não se pode negar que muitas das abordagens empregadas nasceram ou foram inspiradas nas experiências vivenciadas nas salas de aula tradicionais dos "professores-autores" (PIMENTEL et al., 2010) que elaboram o material didático e o plano de curso das disciplinas virtuais.

Os casos tratados neste artigo apresentam esta trajetória. Foram inspirados na dinâmica de interação proposta aos alunos em disciplinas presenciais ministradas desde 2007 pela autora junto ao Departamento de Tecnologia da Arquitetura e do Urbanismo, na Escola de Arquitetura da UFMG. Essa dinâmica baseia-se na possibilidade de criação de diálogo entre os alunos, que, por meio da realização de duas atividades, a resenha e a crítica, devem estabelecer uma interlocução que se desenvolve em um rodízio subsequente: o grupo 2 lê e critica a resenha do grupo 1; o grupo 3, a do grupo 2, e assim por diante. Essa estrutura foi transportada para o plano virtual, partindo-se da percepção/intuição de que no EAD, além do fornecimento da informação, haveria de se criar um mecanismo em que os alunos também pudessem ser autores do processo, já que o espaço virtual de ensino requer maior autonomia de aprendizado por parte dos estudantes.

O argumento de Mello et al. (2010) corrobora essa ideia quando esclarece que os ambientes virtuais devem contribuir "para a construção de novos espaços, capazes de beneficiar a comunicação entre professores e alunos e destes entre si, possibilitando, assim, novas oportunidades para que o aluno possa participar de forma mais ativa no processo de ensino-aprendizagem". 
Por um lado, a dinâmica de interação adotada, baseada nas atividades "resenha/crítica", mostrou-se bastante adaptável ao conceito de "aula-pesquisa". De acordo com Moran (2000), técnicas inovadoras no ensino devem lançar mão de suportes multimídia que podem ser: telemáticos, audiovisuais, textuais, orais, musicais, lúdicos e corporais. Seus usos permitem a realização de "aulas-informação", momento em que são apresentados conteúdos e conceitos pelo professor, e "aulas-pesquisa", quando os alunos buscam, eles próprios e sob orientação do professor, complementar os conteúdos adquiridos, reforçando o aprendizado. Por outro lado, o Ambiente Virtual de Aprendizagem utilizado pela UFMG, o software livre Moodle (Modular ObjectOriented Dynamic Learning Environment), possui recursos que permitiram a viabilização da dinâmica e estrutura proposta.

Sendo assim, a estrutura trabalhada (Figura 1) configurou-se basicamente em módulos constituídos de "aula-informação" e "aula-pesquisa" e, também, de "auladiscussão", criada nesta experiência e que se refere ao fórum de debate, dedicado às discussões de encerramento das atividades de cada módulo, na qual também o professor se envolve na dinâmica, pontuando sobre os comentários e destacando os principais fatores de aprendizado.

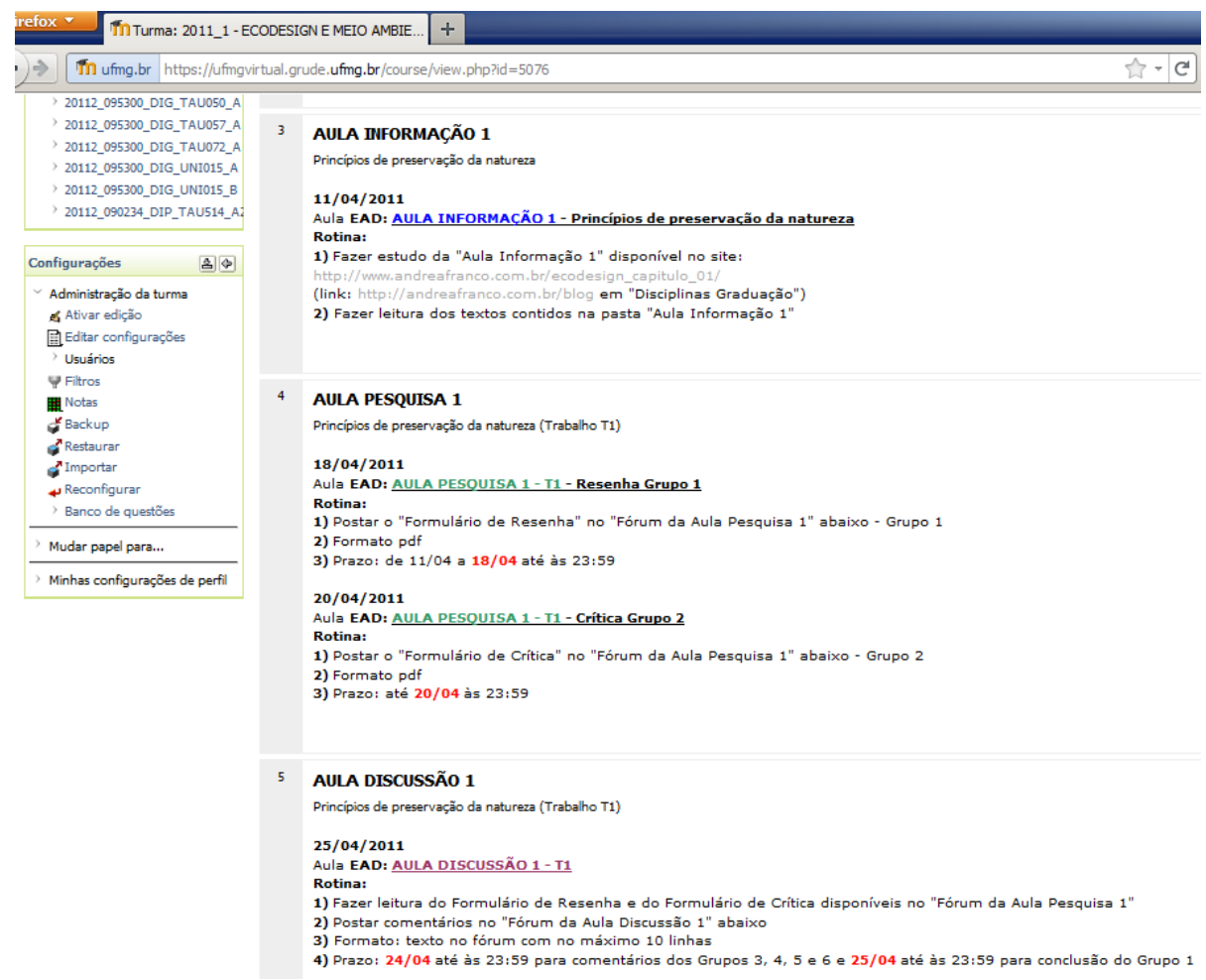

Figura 1 - Estrutura proposta para as disciplinas em EAD, TAU070 e UNI015, EA/UFMG: módulo composto por aula-informação, aula-pesquisa e aula-discussão. 


\section{ELABORAÇÃO DOS OBJETOS VIRTUAIS DE APRENDIZAGEM}

A elaboração do material didático para o a EAD deve ser centrada no usuário, ou seja, no aluno virtual que utilizará esses materiais em seu processo de aprendizagem. Ressalta-se que o material didático deve permitir a criação de uma "comunidade de aprendizado", tendo em vista que o aluno virtual tem se mostrado mais disposto a colaborar em aprendizagem coletiva (PIMENTEL et al., 2010).

Baseando-se na experiência desenvolvida pelo MEC, Pimentel et al. (2010) propõem alguns indicadores para avaliação de cursos de graduação na modalidade a distância, sabendo-se que em alguns cursos não serão encontrados nem avaliados todos os indicadores propostos. No que tange aos materiais didáticos, esses indicadores dizem respeito a: material impresso (arquivos doc., pdf. etc.), material para rádio, material audiovisual, interdisciplinaridade, uso de Objetos Virtuais de Aprendizagem (OVA), conteúdo da disciplina, material na internet (WEB), articulação e complementaridade entre os materiais, mecanismos para autoavaliação dos alunos, atividades avaliativas obrigatórias, mecanismos gerais de interação.

De acordo com Pimentel et al. (2010), a “EAD tem se utilizado de OVA para a explicação, demonstração e exercícios (por vezes avaliativos) de conteúdos, sendo muitas vezes agrupados em repositórios virtuais", ou seja, que se apoiam em Ambientes Virtuais de Aprendizagem, tais como a plataforma Moodle. Os critérios para avaliação da eficácia dos Objetos Virtuais de Aprendizagem podem ser: imagens, interatividade, interação, adequação, usabilidade, acessibilidade, navegação, aprendizado colaborativo e dialogicidade (PIMENTEL et al., 2010).

No desenvolvimento do EAD, como coloca Machado (2010b), deve-se "acrescentar o ato de se compreender as expectativas dos aprendentes quanto à sua percepção de estar presente ou não numa espécie de comunidade de aprendizado que são os ambientes virtuais". Os ambientes virtuais de aprendizagem devem ser, portanto, "mais amigáveis e mais próximos das vontades, quereres, sentimentos e sensações dos usuários" (MACHADO, 2010b).

A elaboração dos Objetos Virtuais de Aprendizagem expostos nos casos deste artigo partiu desse princípio de concepção centrada no usuário - princípio este que, aliás, é fundamento básico para a prática do design (ICSID, 2010), cuja metodologia foi aplicada na elaboração dos materiais aqui tratados. 
Os Objetos Virtuais de Aprendizagem foram elaborados inicialmente a partir da concepção da disciplina Noções de Design (UNI 015) e contou com recursos financeiros da Pró-Reitoria de Graduação (Prograd) da UFMG, disponibilizados em edital para elaboração de material didático. Uma equipe de trabalho foi composta pela autora e três bolsistas alunos de graduação do Curso de Design. A orientação dos bolsistas, realizada em reuniões periódicas, foi conduzida como prática de desenvolvimento de projeto aplicando as técnicas da Metodologia do Design (disciplina ofertada no $1^{\circ}$ e $2^{\circ}$ períodos e ministrada pela autora), que se apoia em três etapas fundamentais: elaboração do conceito a ser trabalho, configuração da proposta e execução da solução.

O projeto baseou-se, pois, em conceito fundamentado na sensibilização dos usuários - ou seja, até 150 alunos virtuais oriundos dos mais variados cursos de graduação da UFMG - de modo a convidá-los a se matricularem na disciplina a fim de participarem de uma comunidade de aprendizagem abordando conteúdos gerais sobre a prática profissional do design. Haveria de se propor materiais variados e dinâmicos que despertassem interesse e favorecessem o envolvimento dos alunos. O Quadro 1 mostra a estrutura desenvolvida, que será detalhada adiante nos dois casos apresentados.

Quadro 1 - Estrutura de aprendizado desenvolvida para EAD da disciplina Noções de Design

\begin{tabular}{|c|c|c|}
\hline $\begin{array}{l}\text { Momento de } \\
\text { interação } \\
\text { professor-aluno, } \\
\text { aluno-aluno } \\
\end{array}$ & Objetos Virtuais de Aprendizagem & Mecanismos de interação \\
\hline $\begin{array}{l}\text { Período de matrí- } \\
\text { cula }\end{array}$ & - Vídeo de divulgação & $\begin{array}{l}\text { - Links em sites institucionais: UFMG e } \\
\text { Colegiado do Curso de Design }\end{array}$ \\
\hline Aula-informação & $\begin{array}{l}\text { - e-book } \\
\text { - Pasta com sinopse } \\
\text { - Pasta com textos complementares } \\
\text { - Pasta com vídeos complementares }\end{array}$ & $\begin{array}{l}\text { - Site/blog auxiliar } \\
\text { - Recursos do Moodle (rótulo e pasta) } \\
\text { - Rotina detalhada em rótulo no Moodle }\end{array}$ \\
\hline Aula-pesquisa & $\begin{array}{l}\text { - Resenha sobre aula-informação reali- } \\
\text { zada por um grupo de alunos } \\
\text { - Crítica da resenha realizada por outro } \\
\text { grupo ou pelos demais alunos }\end{array}$ & $\begin{array}{l}\text { - Recursos do Moodle (rótulo e fórum) } \\
\text { - Rotina detalhada em rótulo no Moodle } \\
\text { - Formulário de resenha e de crítica } \\
\text { para preenchimento pelos alunos }\end{array}$ \\
\hline Aula-discussão & $\begin{array}{l}\text { - Comentário sobre resenha e crítica em } \\
\text { texto direto no fórum }\end{array}$ & $\begin{array}{l}\text { - Recursos do Moodle (rótulo e fórum) } \\
\text { - Rotina detalhada em rótulo no Moodle }\end{array}$ \\
\hline Avaliação final & - Autoavaliação ou trabalho final & $\begin{array}{l}\text { - Recursos do Moodle (rótulo e tarefa) } \\
\text { - Rotina detalhada em rótulo no Moodle } \\
\text { - Formulário de avaliação final }\end{array}$ \\
\hline
\end{tabular}




\section{CASOS VIVENCIADOS}

\subsection{Disciplina Noções de Design}

A disciplina Noções de Design está a cargo do Departamento de Tecnologia da Arquitetura e do Urbanismo da EA/UFMG, integrando a grade de disciplinas do Curso de Design. Entretanto, recebe o código UNI015, "UNI" designando aquelas disciplinas que são ofertadas para alunos da universidade não matriculados no curso de graduação de origem da disciplina. Nesse sentido, a disciplina é aberta a toda a comunidade da UFMG.

Sua concepção baseia-se no argumento da interseção que o design faz (ou pode fazer) com as diversas áreas do conhecimento. Design é uma atividade de caráter inter e multidisciplinar, que requer a interação de vários profissionais e o estabelecimento de equipes de projeto que, dependendo da área de atuação, tendem a se constituir em função de suas afinidades disciplinares e ideológicas. Atuando para permitir que produtos e peças gráficas cumpram funções de uso (facilidade, conforto, adequação, performance) e de estima (fatores simbólicos, psicológicos, ideológicos, culturais, morais), é um campo propício para atrair interesse de estudantes de áreas humanas, exatas, biológicas etc.

Os principais objetivos de sua oferta em sistema de EAD foram estimular a demanda pela disciplina, já ofertada em semestre anterior em sistema presencial com número muito baixo de inscritos, e permitir a absorção de grande número de estudantes, favorecendo a flexibilização curricular. A disciplina tem sido aberta para 150 alunos. Em sua primeira edição em EAD, no segundo semestre de 2010, participaram 45 alunos; em sua segunda edição, segundo semestre de 2011, há 70 alunos inscritos.

Em 2010, o material didático foi preparado pela autora e bolsistas, mas a disciplina foi ministra por outros dois professores na modalidade semipresencial. Essa experiência permitiu compreender o caráter de flexibilidade e adaptabilidade que os materiais desenvolvidos devem possuir, além de ter dado subsídios para seu aprimoramento, implantado na segunda versão, que vem sendo conduzida na modalidade totalmente a distância.

A ementa da disciplina propõe que sejam tratados conteúdos referentes aos conceitos associados ao design, dirigidos para público extra Curso de Design; à evolução formal e tecnológica do design; ao panorama das principais correntes e "escolas" 
de design; ao design no Brasil; aos princípios da profissão, áreas de atuação do designer e interdisciplinaridade com outras áreas do conhecimento. Esses conteúdos foram, então, compreendidos em módulos ministrados a partir de aula-informação, aulapesquisa, aula-discussão e avaliação final, como mostra o Quadro 1.

A fim de alcançar os objetivos da disciplina, ou seja, ampliar o número de alunos inscritos, um vídeo de apresentação, sob o título Onde tem Design?, foi produzido (ainda em finalização) com o intuito de apresentar situações diversas de aplicação e interação do design com as áreas do conhecimento definidas pela UFMG: Ciências Agrárias, Ciências Biológicas, Ciências Exatas e da Terra, Ciências Sociais Aplicadas, Engenharias, Ciências da Saúde, Ciências Humanas, Linguística, Letras e Artes.

Um e-book foi desenvolvido para a aula-informação. Garantindo a proteção dos direitos autorais, esse material foi registrado na Biblioteca Nacional (com obtenção de ISBN), podendo ser consultado via acesso a um site auxiliar de hospedagem: http://andreafranco.com.br/blog/. Além disso, a aula-informação apresenta uma sinopse do conteúdo a ser tratado no módulo, contendo bibliografia complementar e links para alguns sites interessantes relacionados ao tema. São ainda fornecidos textos complementares para leitura, muitos deles publicados em veículos científicos, e links para alguns vídeos contendo entrevistas ou divulgações, que possam complementar o aprendizado.

A aula-pesquisa refere-se ao momento em que os alunos buscam, eles próprios, complementar os conteúdos adquiridos, reforçando o aprendizado. Pode ser conduzida com atividades de elaboração de resenha e de críticas, para as quais são fornecidos formulários contendo as descrições das tarefas e os critérios de avaliação, que inclui a elaboração de uma contribuição de conteúdo. Esses formulários devem ser convertidos em arquivos pdf. e postados no fórum reservado para esse fim. O objetivo do uso do fórum é o de permitir a consulta das contribuições por todos os demais alunos, tutores e professor.

A aula-discussão, por sua vez, é consequência da dinâmica trabalhada na aula-pesquisa. Seu objetivo é permitir a participação dos demais alunos (aqueles que realizam resenhas dos outros módulos), emitindo comentários sobre as resenhas postadas. Os autores das resenhas também devem participar das discussões fazendo a conclusão do assunto, assim como o professor e tutores. Para tanto, utiliza-se também a ferramenta fórum para a visualização, por todos os participantes, dos comentários postados, que são feitos diretamente na janela de texto, em um limite de 10 linhas. 
Por fim, uma sessão é reservada à avaliação final, podendo ser em sistema de autoavaliação ou entrega de trabalho. Para ambas são fornecidos formulários contendo as descrições das tarefas e os critérios de avaliação. Esses formulários, convertidos em arquivos pdf., devem ser postados no dispositivo "tarefa", que, ao contrário do fórum, não permite a visualização e acesso pelos demais participantes, resguardando as opiniões omitidas.

\subsection{Disciplina Ecodesign e Meio Ambiente}

A disciplina Ecodesign e Meio Ambiente integra a grade de disciplinas do Curso de Design e é uma das 38 disciplinas optativas ofertadas pelo curso. Garante ao aluno 3 créditos e recebe o código TAU070, designando que está a cargo do Departamento de Tecnologia da Arquitetura e do Urbanismo da EA/UFMG. Cabe informar que a estrutura curricular do Curso de Design foi baseada em uma proposta de flexibilização do ensino, sendo composta por 125 créditos obrigatórios e 106 créditos optativos. Sendo assim, a oferta das disciplinas optativas ganha maior importância, tendo em vista que, para a integralização do curso, os alunos devem cumprir 30\% da carga horária em optativas, totalizando 55 créditos. O Colegiado de Graduação do Curso de Design estabeleceu que as disciplinas optativas somente fossem ofertadas nas segundas e terçasfeiras, estando esses dias reservados para essas disciplinas, a fim de garantir maior número de alunos em condições de se matricularem nas diversas disciplinas ofertadas.

Diante disso, o objetivo da oferta da disciplina Ecodesign e Meio Ambiente na modalidade EAD foi o de permitir que os alunos pudessem cursar maior número de disciplinas optativas, contornando a sobreposição de horários que ocorreria em situação de aulas presenciais.

Na realidade, a disciplina Ecodesign e Meio Ambiente na modalidade EAD foi concebida com base na experiência anterior vivenciada com a condução da primeira edição da disciplina Noções de Design. Concluiu-se que seria uma ótima oportunidade para se experimentar uma prática de ensino quase totalmente a distância (houve três encontros presenciais para apresentação de trabalho final) em uma turma com número menor de alunos. A disciplina foi ofertada no primeiro semestre de 2011 e contou com a participação de 25 alunos.

Sua ementa propõe que sejam tratados conteúdo tais como princípios de preservação da natureza, meio ambiente e qualidade de vida; fatores e processos ecológi- 
cos fundamentais no planejamento de estratégias de desenvolvimento sustentável e o estudo das ferramentas e métodos de ecodesign. Esses conteúdos foram, então, compreendidos em módulos ministrados a partir de aula-informação, aula-pesquisa, auladiscussão e avaliação final, como mostra o Quadro 1, que foram trabalhados de maneira semelhante àquela descrita anteriormente para a disciplina Noções de Design.

Os resultados alcançados nessa experiência foram acima do esperado. Observou-se um envolvimento intenso dos participantes nas atividades de interação estabelecidas nos fóruns. Os alunos se engajaram nas tarefas, trazendo contribuições interessantes de conteúdos, tanto na realização das resenhas quanto nas críticas. Houve um trabalho prático apresentado presencialmente ao final, ocasião em que os alunos puderam se expressar quanto aos resultados da disciplina. A maioria das manifestações referiu-se à superação das expectativas em relação ao sistema de EAD (nenhum aluno teve essa experiência anteriormente), ao aprendizado adquirido e ao envolvimento na elaboração do trabalho final, fruto do conhecimento apreendido nas tarefas anteriores. Alguns fizeram sugestões de melhorias referentes à apresentação de maior número de exemplos reais de aplicação do assunto. Ao final, foi proposta uma autoavaliação, que seria postada via ferramenta "tarefa" no Moodle, contendo autoavaliação quanto à participação e quanto ao aprendizado adquirido. Os resultados dos "depoimentos" foram surpreendentes e corroboraram a eficiência da abordagem. Em relação ao aproveitamento, mais de $50 \%$ da turma alcançou conceito A.

A Figura 2 mostra algumas questões da avaliação da disciplina feita pela turma. Dos 25 alunos que participaram da disciplina, 24 responderam o questionário (houve 29 inscritos, quatro desistentes). Os conceitos "bom" e "muito bom" foram considerados por $65 \%$ e $72 \%$ dos alunos nas questões referentes à adequação dos conteúdos estudados à carga horária, ao material didático utilizado, à bibliografia indicada e aos procedimentos de avaliação da aprendizagem utilizados. Quando questionados se recomendariam a um colega cursar essa disciplina, 100\% dos participantes responderam que sim. 


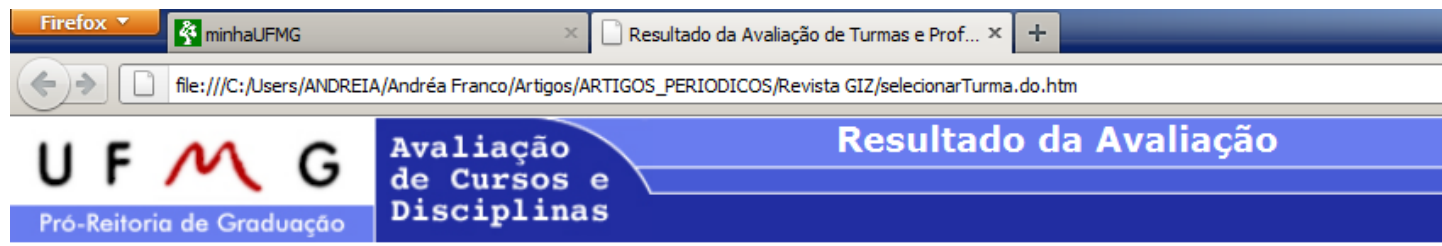

Semestre: 2011/1

Ofertante: 095300 EA - DESIGN

Disciplina: TAU070 ECODESIGN E MEIO AMBIENTE

Turma: A

\section{Avaliação da Turma}

Total de questionários: 29

\section{Questão 11}

Adequação dos conteúdos estudades à carga horária

Não respondeu:

Muito Ruim :

Ruim :

Médio :

Bom :

Muito Bom :

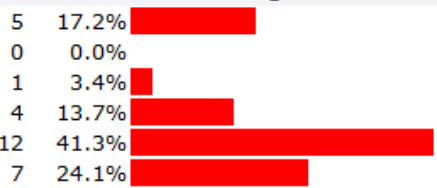

\section{Questão 12}

Material didático utilizado

Não respondeu:

Muito Ruim :

Ruim :

Médio :

Bom :

Muito Bom :

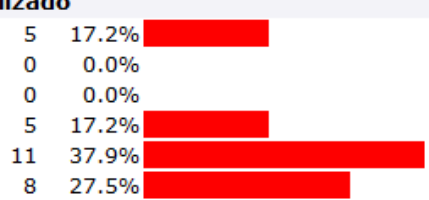

\begin{tabular}{lrr}
$\begin{array}{l}\text { Questão } 13 \\
\text { Bibliografia indicada }\end{array}$ & \\
Não respondeu: & 5 & $17.2 \%$ \\
Muito Ruim : & 0 & $0.0 \%$ \\
Ruim : & 0 & $0.0 \%$ \\
Médio : & 3 & $10.3 \%$ \\
Bom : & 11 & $37.9 \%$ \\
Muito Bom : & 10 & $34.4 \%$ \\
\hline
\end{tabular}

Questão 14

Procedimentos de avaliação da aprendizagem utilizados

Não respondeน:

Muito Ruim :

Ruim :

Médio :

Bom :

Muito Bom :

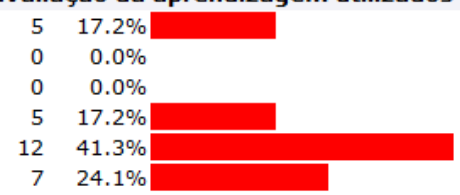

Figura 2 - Algumas questões da avaliação da turma para a disciplina TAU070 Ecodesign e Meio Ambiente. Fonte: Sistema de Avaliação de Cursos e Disciplinas Prograd/UFMG.

Como em um ciclo de aprendizado, essa experiência forneceu subsídios para a proposta totalmente virtual da segunda edição da disciplina Noções de Design. 


\section{CONSIDERAÇÕES FINAIS}

O trabalho desenvolvido foi bastante proveitoso no que diz respeito à compreensão sobre as possibilidades apresentadas pelo uso do EAD e dos Ambientes Virtuais de Aprendizado. Alguns pontos do conhecimento adquirido merecem destaque, tais como o cuidado que se deve ter em relação à elaboração dos materiais didáticos e à precisão de sua comunicação no ambiente virtual: organização, padronização da formatação, informações claras e objetivas, autoria e fontes de consulta referenciadas de maneira clara e correta. Além disso, deve-se ter atenção em resguardar a autoria dos materiais inéditos produzidos, tais como e-books e vídeos. Algumas dificuldades encontradas estão relacionadas à falta de recursos financeiros e humanos para a elaboração de alguns materiais didáticos, como os vídeos, que exigem maior conhecimento técnico para sua produção e edição. O uso dos Ambientes Virtuais de Aprendizado, especificamente o sistema Moodle, pode ser dificultado por embaraços de usabilidade de edição, lentidão do sistema ou falhas de conexão.

Não obstante, as experiências apresentadas neste artigo reforçam a ideia de que o EAD apresenta grande potencial nas práticas de ensino na graduação. Por um lado, a elaboração de materiais didáticos utilizando-se de suporte multimídia divulgados em ambientes virtuais é promissora. Por outro, os alunos se mostram muito abertos e adaptados aos sistemas virtuais de comunicação, interação e aprendizado. Além disso, essa modalidade pode ser também bastante interessante no ensino da pósgraduação. O material da aula-informação da disciplina Ecodesign e Meio Ambiente foi utilizado em EAD em disciplina do mestrado, obtendo grande aceitação por parte dos alunos, que em aulas presenciais discutiram e avançaram o conhecimento com base na leitura daqueles materiais.

\section{AGRADECIMENTO}

À Pró-Reitoria de Graduação (Prograd/UFMG), pelos recursos financeiros concedidos.

\section{REFERÊNCIAS BIBLIOGRÁFICAS}

ABRAEAD - Anuário Brasileiro Estatístico de Educação a Distância. Disponível em: <http://www.abraead.com.br/noticias.cod=x1.asp>. Acesso em: 29/08/2011. 
CRUZ, Dulce Márcia. A construção do professor midiático: o docente comunicador na educação a distância por videoconferência. Cadernos de Educação, FaE/PPGE/UFPel, Pelotas, n. 30, p. 201-214, janeiro/junho 2008.

ICSID - International Council of Societies of Industrial Design. Disponível em: <http://www.icsid.org/>. Acesso em: 29/08/2011.

MACHADO, Glaucio José Couri (Org.). Educação e ciberespaço: estudos, propostas e desafios. Aracaju: Virtus, 2010a. p. 255-307.

MACHADO, G. J. C. Haveria de existir sentimento de presença nos ambientes virtuais de aprendizagem? In: MACHADO, Glaucio José Couri (Org.). Educação e ciberespaço: estudos, propostas e desafios. Aracaju: Virtus, 2010b. p. 236-254.

MELLO, B. A.; SILVA, D. R., KURTZ, F. D. Ambientes virtuais de aprendizagem: uma discussão sobre concepções, funcionalidades e implicações didáticas. In: MACHADO, Glaucio José Couri (Org.). Educação e ciberespaço: estudos, propostas e desafios. Aracaju: Virtus, 2010. p. 255-307.

MORAN, J. M. Ensino e aprendizagem inovadores com tecnologia. In: MORAN; MASETTO; BEHRENS. Novas tecnologias e mediação pedagógica. São Paulo: Papirus Editora, 2000. Disponível em: <http:/ / www.scribd.com/doc/2525970/Moran-Ensinoe-aprendizagem-inovadores-com-tecnologia>. Acesso em: 26/10/2009.

PIMENTEL, F. S. C.; PINTO, A. C.; MERCATO, L. P. L. Indicadores para avaliação de cursos em EAD. In: MACHADO, Glaucio José Couri (Org.). Educação e ciberespaço: estudos, propostas e desafios. Aracaju: Virtus, 2010. p. 208-235. 